九州大学学術情報リポジトリ

Kyushu University Institutional Repository

\title{
Analysis of the Diameter Distribution of Plantations Using the Weibull Distribution
}

Kakihara, Michiyoshi

University Forests, Faculty of Agriculture, Kyushu University

https://doi.org/10.5109/23822

出版情報：九州大学大学院農学研究院紀要. 30 (2/3)，pp.167-174，1985-12. Kyushu University バージョン：

権利関係 : 
I. Fac. Agr,, Kyushu Univ., 30(2•3), 167-174 (1985)

\title{
Analysis of the Diameter Distribution of Plantations Using the Weibull Distribution*
}

\author{
Michiyoshi Kakihara \\ University Forests, Faculty of Agriculture, \\ Kyushu University, Fukuoka 812
}

(Received September 27,1985)

\begin{abstract}
The Weibull distribution was applied to the diameter distribution of plantations, and how parameters a (min. dia.), b (scale) and c (shape) change with age or by thinning was examined. The results showed that 1) thinning generally used methods decreases parameter c, 2) parameter a was often constant, and parameter c increased up to a certain period after thinning (5-10 years), and 3) when the forests were repeatedly thinned, parameter $c$ tended to decrease with age. These findings show that a thinning method to increase parameter $\mathrm{c}$ must be developed if the purpose of forest management is a forest with large c (negative skewness).
\end{abstract}

\section{INTRODUCTION}

The diameter distribution expresses the characteristics of stand composition well and is used often in studies on stand management technology. However, the characteristics of the diameter distribution have been expressed using only figures and tables, and quantitative explanation of the diameter distribution changes with age or by thinning has not been made. Thus, the diameter distribution has not been used in actual studies on stand management technology. One of the reasons for this is that a probability density function fitting the diameter distribution of plantations well has not been found. Twelve years ago, the Weibull distribution was found to fit the diameter distribution of plantations well (Clutter and Allison, 1973; Robert, 1973), and nine years ago, a simple estimation method of the Weibull parameters was clarlified (Nishizawa et al., 1976; Nishizawa, 1978). Therefore, using the Weibull distribution I have examined how the diameter distribution of plantations changes with age or by thinning, and discussed the problems of thinning methods now being generally used.

\section{DIAMETER DISTRIBUTION OF PLANTATIONS IN THE WEIBULL DISTRIBUTION}

The Weibull distribution used to express the diameter distribution is

* A part of this study was presented at IUFRO symposium on forestry management planning and managerial economics, Tokyo, 1984. 
shown by equation (1).

$$
n_{i}=N w(c / b)\left\{\left(d_{i}-a\right) / b\right\}^{c-1} \exp \left[-\left\{\left(d_{i}-a\right) / b\right\}^{c}\right]
$$

where $n_{i}$ is the number of trees belonging to each diameter class, $d_{i}$ is each diameter class, $\mathrm{N}$ is the total number of trees, $\mathrm{w}$ is the width of diameter class, a, $b$ and c are parameters.

$a$ is the minimum stand diameter; $b$ is the value for a cumulative distribution of diameters at the $63 \%$ point, showing the spread of the distribution. $\mathrm{c}$ is the parameter which expresses the shape of the distribution. For example, when $c<3.6$ the distribution has positive skewness, when $c \div 3.6$ the distribution is normal, and when $c>3.6$ the distribution has negative skewness (Fig. 1). Thus, by altering the Weibull parameters the distribution can be made to fit the diameter distribution of plantations. These characteristics of the Weibull distribution show that it fits well with the diameter distribution of plantations which have various shape, and this has been proved by many investigators (Kinashi, 1978; Nishizawa, 1978; Abe, 1980; Takata and Kazama, 1980 ; Kakihara, 1982).

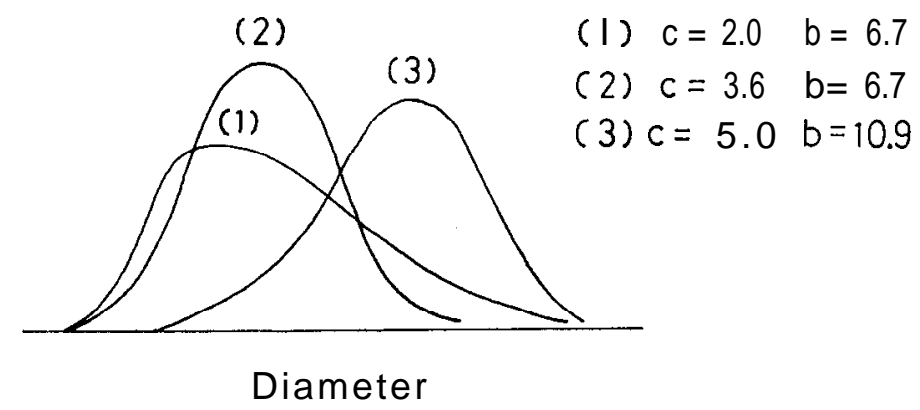

Fig. 1. Different shapes of the Weibull distribution.

\section{CHANGE OF THE WEIBULL PARAMETERS AFTER THINNING}

Using the data obtained from the experimental forests (plots) set up by Forest and Forest Products Research Institute all over Japan, the change of the Weibull parameters a and $\mathrm{c}$ after thinning was examined. The number of plots is 7 for Sugi (Cryptomeria japonica D. Don), 9 for hinoki (Chamaecyparis obtusa Sieb. et Zucc.) and 5 for Karamatsu (Larix leptolepis Gordon). The data (age and the Weibull parameters) obtained from these plots are shown in Table 1. Table 2 shows the change of the Weibull parameters a and $c$ after thinning obtained from Table 1.

Considering Table 2, thinning can be classified into three types.

Type 1: a changes, c decreases

All the trees belonging to the minimum diameter class are felled and c decreases. This type of thinning was found at 20 stands accounting for $63 \%$ of the total. It was the common type of thinning. 
Table 1. Age and the Weibull parameters a and $\mathrm{c}$ at experimental forests.

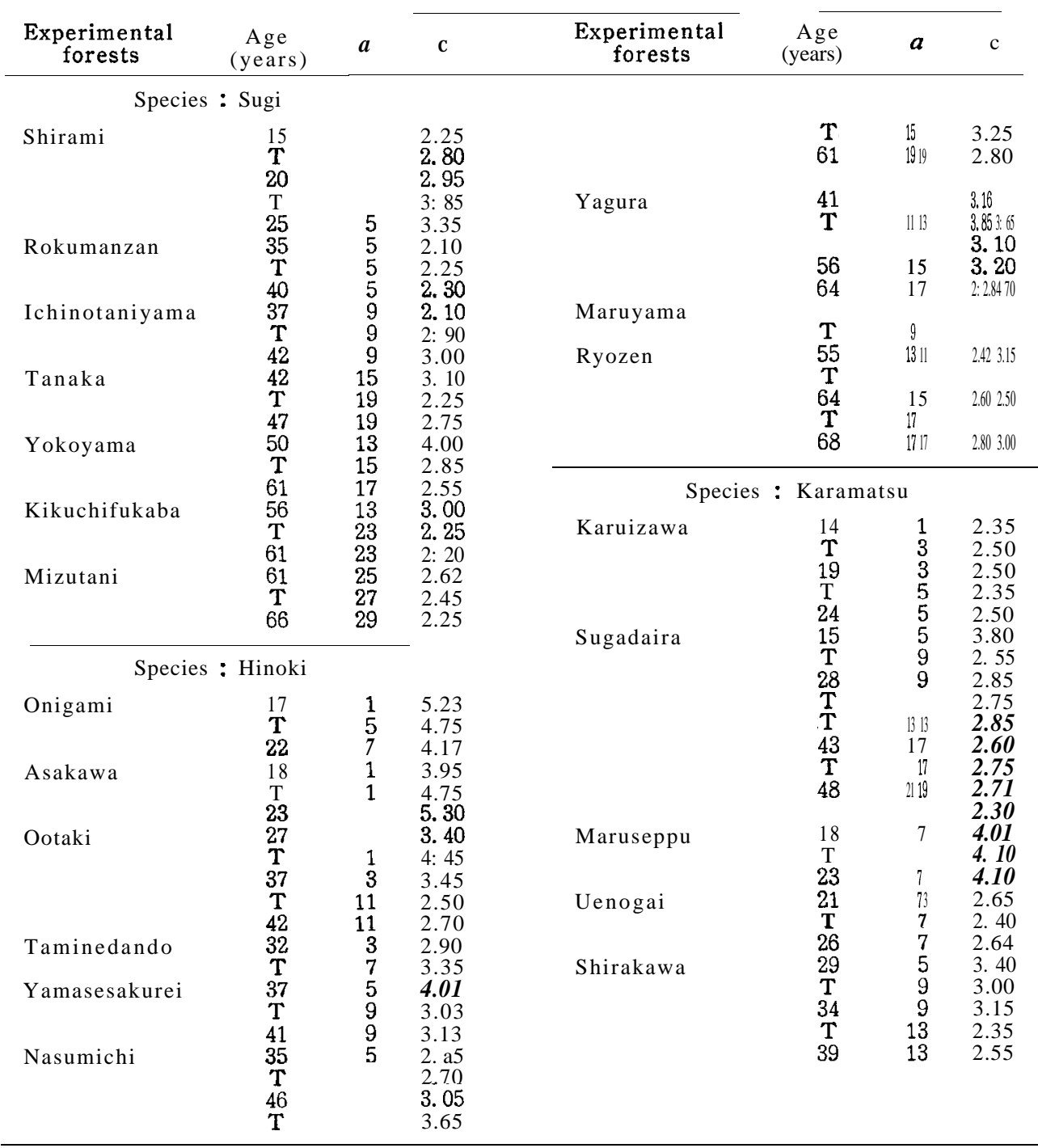

$\mathrm{T}$ shows after thinning.

Table 2. Change of the Weibull parameters a and $\mathrm{c}$ after thinning.

\begin{tabular}{ccccc}
\hline & Sugi & Hinoki & Karamatsu & Total \\
\hline a changes, c decreases & 4 & a & a & 2 \\
a fixed, c increases & 3 & 4 & 0 & 7 \\
a changes. c increases & 1 & 2 & 2 & 5 \\
\hline Total & 8 & 14 & 10 & 32 \\
\hline
\end{tabular}


Type 2: a fixed, c increases

Not all of the trees belonging to the minimum diameter class are felled and $\mathrm{c}$ always increases. This was found at 7 stands accounting for $22 \%$.

Type 3: a changes, c increases

All the trees belonging to the minimum diameter class are felled as in type 1 , but in contrast to type 1 , c increases. This was found at 5 stands, accounting for only $15 \%$. However, when the purpose of forest management is an increase in c, this thinning method should be considered.

Since the plantations are thinned by mainly selecting trees with a small diameter, all the trees belonging to the minimum diameter class are felled. From this standpoint, the types 1 and 3 thinning method meet the purpose of thinning. Since the ratio of type 1 to type 3 is $4: 1$, thinning generally used is regarded to have been made to decrease c.

Next, the change of the Weibull parameters a and $c$ in a certain period after thinning (5-10 years) was examined for 30 stands shown in Table 1. The results are shown in Table 3 .

Table 3. Change of the Weibull parameters a and $c$ in a certain period after thinning (5-10 years).

\begin{tabular}{|c|c|c|c|c|}
\hline & Sugi & Hinoki & Karamatsu & Total \\
\hline a changes, c decreases & 3 & 6 & 1 & 10 \\
\hline a fixed, $\quad c$ increases & 4 & 6 & 7 & 17 \\
\hline $\mathrm{c}$ is no change & 0 & 0 & 2 & 2 \\
\hline a fixed, $\quad c$ decreases & 1 & 0 & 0 & 1 \\
\hline Total & 8 & 12 & 10 & 30 \\
\hline
\end{tabular}

When a changed, c always decreased. On the other hand, when a is fixed, c increased in $85 \%$ of the cases. Therefore, the change of the Weibull parameters from thinning to the end of a certain period (5-10 years) can be classified into the following two types.

Type 1: a changes, c decreases

All the trees in the class having the smallest diameter grow to have a diameter of the next higher class, and c decreases.

Type 2: a fixed, c increases

Some of the trees in the class having the smallest diameter do not grow to have a diameter of the next higher class. c increases.

The ratio of type 1 to type 2 was $1: 1.7$, the latter being slightly larger.

Next, the change of parameters a and $c$ with passage of time; before thinning-after thinning-after a certain period was summarized using Table 1 , and shown in Table 4. The type of most of Karamatsu was a changes, c decreases $\rightarrow a$ fixed, c increases, being seen 7 out of 10 cases. Therefore, Karamatsu considered to generally repeat the change of 1) a changes by thinning, and c decreases, 2) after a certain period, a fixed and c decreases, and 3) thining is carried out again and a changes and c decreases. This is clearly 
Table 4. Change of the Weibull parameters a and $c$ with passage of time.

\begin{tabular}{|c|c|c|c|c|}
\hline & Sugi & Hinoki & Karamatsu & Total \\
\hline a changes, $\mathrm{c}$ decreases $\rightarrow$ a fixed, $\mathrm{c}$ increases & 1 & 4 & 7 & 12 \\
\hline a changes, $c$ decreases-t a changes, $c$ decreases & 2 & 4 & 1 & 7 \\
\hline a fixed, c increases $\rightarrow$ a fixed, c increases & 3 & 2 & 0 & 5 \\
\hline Others & 2 & 2 & 2 & 6 \\
\hline Total & 8 & 12 & 10 & 30 \\
\hline
\end{tabular}

shown in the example of Sugadaira exprimental forests shown in Table 1. For Sugi and Hinoki, there were many types, no particular type such as that found for Karamatsu being seen. However, when thinning was repeated twice, a increased and c decreased as seen in the example of the experimental forests at Ootaki and Yagura.

\section{CHANGE OF THE WEIBULL PARAMETERS OBTAINED FROM YIELD TABLES}

The yield table shows the value of stand factors for age when a forest was grown by appropriate thinning. Therefore, if the Weibull parameters could be estimated for age from the yield table, the change of the diameter distribution when a forest was grown by appropriate thinning can be predicted. Therefore, the Weibull parameters for each age in the yield table were estimated by the method of Nishizawa (Nishizawa et al., 1977; Nishizawa, 1978). The yield tables for Sugi in Kumamoto districts, for Hinoki in Shinshu districts and for Karamatsu in Hokkaido districts (Hayao, 1961) were used in this study. The prediction method for 20-year-old Sugi is as follows.

Shown in Table 5 , the mean diameter $(\bar{d})=16.6 \mathrm{~cm}$, number of trees per ha $(N)=1,708$ and basal area per ha $(B)=37.2 \mathrm{~m}^{2}$, I estimate the diameter of average basal area $\left(\bar{d}_{b}\right)$, standard deviation (s) and variation coefficient of diameters $\left(C V_{d}\right)$ as

$$
\begin{aligned}
& \bar{d}_{b}=\sqrt{(\bar{B} / N)(4 / \pi)(100)=\sqrt{(37.2 / 1}, 708)(4 / \pi)(100)}=16.7 \mathrm{~cm} \\
& s=\sqrt{\left(\overline{d_{b}} / \bar{d}\right)^{2}-1}=\sqrt{(16.7 / 16.6)^{2}-1}=1.8 \mathrm{~cm} \\
& C V_{d}=s / \bar{d}=1.8 / 16.0=0.11
\end{aligned}
$$

When $a=9, E(X)=(a-a)=(16.6-\mathrm{g})=7.6$. Then, the variation coefficient of $\mathrm{X}\left(C V_{x}\right)$ is estimated as

$$
C V_{x}=[1+a / E(X)] C V_{a}=[1+9 / 7.6](0.11)=0.24
$$

From table corresponding to $C V_{x}$ (Nishizawa, 1978), when $C V_{x}=0.24$, I find $c=4.50\left(\Gamma_{1}=0.90\right)$, hence $b=E(X) / \Gamma_{1}=7.6 / 0.90=8$. 4. Substituting $\mathrm{N}=1,708$, $w=2, a=9, b=8.4$ and $c=4.5$ in equation (1), I have

$$
\left.n_{i}=(1,708)(2)(4.5 / 8.4)\left\{\left(d_{i}-9\right) / 8.4\right\}^{3.5} \exp \left[-\left\{d_{i}-9\right) / 8.4\right\}^{4.5}\right]
$$

By setting $d_{i}=10$ in the above equation, I find that the number of 
trees for the minimum diameter class is very few, i. e., $n_{t}=1.06$. Thus, I decide the Weibull parameters for 20-year-old as $a=9, b=8.4$ and $c=4$.5. By this method, the Weibull parameters for each age were estimated. The results are shown in Table 5.

Table 5. Each factors of yield tables and estimated the Weibull parameters.

\begin{tabular}{|c|c|c|c|c|c|c|c|}
\hline $\begin{array}{c}\text { Age } \\
\text { (years) }\end{array}$ & $\begin{array}{l}\text { Mean } \\
\text { height } \\
\text { (m) }\end{array}$ & $\begin{array}{c}\text { Mean } \\
\text { diameter } \\
(\mathrm{cm})\end{array}$ & $\begin{array}{l}\text { No. of trees } \\
\text { per ha }\end{array}$ & $\begin{array}{c}\text { Basal area } \\
\text { per ha } \\
\left(\mathrm{m}^{2}\right)\end{array}$ & W & $\begin{array}{l}\text { par } \\
b\end{array}$ & $\begin{array}{l}\text { eter } \\
\text { C }\end{array}$ \\
\hline \multicolumn{8}{|c|}{ Species : Sugi } \\
\hline 20 & 10.8 & 16.6 & 1,708 & 37.2 & 9 & 8.40 & 4.50 \\
\hline 30 & 14.9 & 22.7 & 1.132 & 47.4 & 13 & 10.90 & 2.40 \\
\hline 40 & 18.4 & 27.9 & a47 & 54.4 & 13 & 16.74 & 2.45 \\
\hline 50 & 21.5 & 32.6 & 675 & 59.4 & 15 & 19.78 & 2. 40 \\
\hline 60 & 24.3 & 36.9 & 559 & 63.2 & 17 & 22.36 & 2.40 \\
\hline 70 & 26.8 & 40.9 & 475 & 66.2 & 19 & 24.28 & 2,10 \\
\hline 80 & 29.0 & 44. 3 & 411 & 68.7 & 19 & 28.43 & 2. 10 \\
\hline \multicolumn{6}{|c|}{$\boldsymbol{r}: 0.97$} & 0.99 & -0.78 \\
\hline \multicolumn{8}{|c|}{ Species : Hinoki } \\
\hline 20 & 8.4 & 11.4 & 2,280 & 23.8 & 5 & 6.96 & 5.00 \\
\hline 30 & 12.3 & 16.5 & 1,148 & 32.2 & 9 & 8.24 & 3.90 \\
\hline 40 & 15.9 & 21.0 & 1,080 & 38.2 & 11 & 10.89 & 3.90 \\
\hline 50 & 19.0 & 25.0 & 850 & 42.8 & 13 & 13.33 & 3.30 \\
\hline 60 & 21.9 & 28.5 & 710 & 46. 3 & 17 & 12.92 & 3.00 \\
\hline \multicolumn{6}{|c|}{$r: 0.99$} & 0.95 & -0.95 \\
\hline \multicolumn{8}{|c|}{ Species : Karamatsu } \\
\hline 20 & 16.4 & 18.2 & 861 & 22.9 & 9 & 10.20 & 3. 70 \\
\hline 30 & 20.9 & 23.8 & 598 & 24.0 & 15 & 9.85 & 3.10 \\
\hline \multirow[t]{2}{*}{40} & 23.5 & 25.3 & 485 & 28.0 & 17 & 12.02 & 2.90 \\
\hline & & & & $\boldsymbol{r}:$ & 96 & 0.77 & -0.96 \\
\hline
\end{tabular}

r: Correlation coefficient between age and the Weibull parameters.

The Weibull parameters correlated well with age, i. e., a and $b$ increased and $c$ decreased with age. These results show that with age, 1) the minimum diameter increases, 2) the spread of the distribution increases and 3) the skewness of the shape of the distribution increases.

These results, particularly the changes in a and $\mathrm{c}$ are in good agreement with results of the previous studies made at the experimental forests. Therefore, the increase in a and decrease in $c$ with age is a large characteristics of the change in the diameter distribution of plantations.

\section{DISCUSSION}

As is clear from above, in the plantations of Japan, a thinning method by which the Weibull parameter $\mathrm{c}$ is decreased is generally used, and as a result, 
a plantations with a small $\mathrm{c}$ is made. If the purpose of forest management is to make a forest with small c, the present method of thinning is not a problem. However, in a forest with a small $c$, the variation coefficient of diameters is large, and forest has trees with variable diameters. Therefore, the establishment of a forest with small $\mathrm{c}$ is not always the best. In some cases, it would be better to make a forest with a smaller variation coefficient of diameters (homogeneous diameters). In such cases, traditional thinning regimes are not appropriate, and a thinning method to make parameter c large must be devised. The following two methods are possible. One is the thinning method based on thinning percentage for each diameter class by analyzing in datail the type 3 thinning (Kakihara and Kinashi, 1983). Another is to fell the trees with a large diameter to increase c (Kakihara and Kinashi, 1985). In either case, I have set up an experimental plot for thinning, and are examining these possibilities. Whether these two methods are good is not certain, but I believe that I can obtain information leading to a new method of thinning. The new method of thinning to increase $c$ was devised from the analysis of the change in the diameter distribution. I would like to stress the effectiveness of the Weibull distribution in the future studies on thinning.

\section{ACKNOWLEDGEMENTS}

I am greatly indebted to Prof. Emerit. K. Kinashi of Kyushu University for his valuable advice on the Weibull distribution and thinning. I also wish to experess my hearty thanks to Prof. T. Aoki of Kyushu University for his suggestion. Finally I thank Dr. H. Awaya and Mr. E. Morita, Chief Researcher, Forest and Forest Products Research Institute, who provided the data used in this study.

\section{REFERENCES}

Abe, N. 1980 Studies on management of Abies sacalinensis Mast planted forest. (II) Yield table of Abies sacalinensis in Hokkaido prefectural forest. Bull. Hokkaido For. Exp. Sta., 18: 211-216 (in Japanese with English summary)

Clutter, J. L. and B. J. Allison 1973 A growth and yield model for Pinus radiata in New Zealand. IUFRO Proceedings, Vancouver, 61-66

Hayao, U. 1961 The yield tables for Japanese main species. For. Economy Inst. Tokyo, 334-335, 376-377, 466-467 (in Japanese)

Kakihara, M. 1982 The Weibull distribution and its application. J. Jap. For. Statis., 7: 37-43 (in Japanese)

Kakihara, M. and K. Kinashi 1983 Diameter distribution of artificial plantation. (X) Thinning of Cryptomeria japonica artificial plantation based on the thinning percentage for each diameter class. Trans. 93rd. Mtg. Jap. For. Soc., 107-108 (in Japanese)

Kakihara, M. and K. Kinashi 1984 Distribution of diameters in Japanese artificial forests. IUFRO Proceedings, Tokyo, 554-561

Kakihara, M. and K. Kinashi 1985 Diameter distribution of artificial plantation. (XII) Thinning of Pinus Thumbergii young stand. Bull. Kyushu Br. Jap. For. Soc. (in press) 
Kinashi, K. 1978 The study of forest inventory. Noorin shuppan Co. Ltd., Tokyo, pp. 262-292 (in Japanese)

Nishizawa, M. 1978 Estimation methods of stand composition by plotless sampling. IUFRO Proceedings, Bucharest, 220-230

Nishizawa, M., K. Kinashi, M. Kakihara and M. Chyo 1976 The study of growth model for stand simulation. (III) Prediction of future diameter distribution by the estimation of Weibull parameters. Trans. 87th Mtg. Jap. For. Soc., 87-88 (in Japanese)

Nishizawa, M., K. Kinashi, M. Kakihara and M. Chyo 1977 The study of growth model for stand simulation. (IX) Prediction of future diameter distribution by use of the variation coefficient of diameters. Trans. 88th Mtg. Jap. For. Soc., 105-106 (in Japanese)

Takata, K. and Y. Kazama 1980 On the rounding in estimating diameter corresponding to mean basal area. J. Jap. For. Soc,, 62: 211-216 (in Japanese with English summary)

Rebert, L. B. 1973 Weibull model for Pinus radiata diameter distribution. IUFRO Proceedings, Vancouver, 51-55 